\title{
ONTOPOLITICA E DIAGRAMAS HISTÓRICOS DO PODER: MAIORIA E MINORIA SEGUNDO DELEUZE E A TEORIA DAS MULTIDÕES SEGUNDO PEIRCE
}

\section{ONTOPOLITICS AND HISTORICAL DIAGRAMS OF POWER: MAJORITY AND MINORITY ACCORDING TO DELEUZE AND THE THEORY OF MULTITUDES ACCORDING TO PEIRCE}

Hélio Rebello Cardoso Jr.*

RESUMO - Este artigo procura desenvolver o âmbito da assim chamada ontopolítica como contribuição original do pensamento do G. Deleuze para a filosofia política contemporânea. Com este objetivo, veremos que Deleuze toma o conceito de poder em Foucault e lhe confere alçada ontológica. Este conceito de poder dá acesso a outro elemento importante da filosofia política deleuzeana, ou seja, o estudo dos diagramas históricos do poder nas denominadas sociedades disciplinar e de controle. Com o diagrama de funcionamento das mesmas podemos entender qual o retrato deleuzeano para a democracia em sociedades contemporâneas. Adentrando a ontopolítica deleuzeana, nos dedicaremos aos conceitos de maioria, minoria e devir-minoritário. É neste ponto que se faz o encontro da ontopolítica de Deleuze com a ontologia matemática de $\mathrm{Ch}$. Sanders Peirce. Acontece que os conceitos ontopolíticos de Deleuze, além de sua vinculação com uma ontologia do poder, recebem também um tratamento matemático, tendo em vista certas noções aritméticas (contável e não contável) e geométricas (linhas). As maiorias e minorias são conjuntos contáveis que são atravessados por devires não contáveis. Com isso, chegaremos ao ponto central do presente artigo, onde realizamos uma incursão inicial à imagem dos conceitos de maioria e minoria em Deleuze, com

* Livre-docente em Filosofia (UNESP). E-mail: < herebell@hotmail.com>.

\begin{tabular}{|l|l|l|l|l|l|}
\hline Veritas & Porto Alegre & v. 57 & n. 1 & jan./abr. 2012 & p. 153-179 \\
\hline
\end{tabular}


base na teoria das coleções e multidões de C. S. Peirce, principalmente com relação à ontologia matemática nela incluída. Quanto a isso, a principal operação será mostrar de que forma a distinção deleuzeana entre maiorias/minorias contáveis e devir-minoritário não contável pode ser escandida em termos de coleções discretas denominadas enumeráveis, denumeráveis e abnumeráveis ou pós-numeráveis, de acordo com a terminologia de Peirce.

PALAVRAS-CHAVE - Deleuze. Peirce. Ontopolítica. História. Multidões.

ABSTRACT - This article aims at developing the so-called ontopolitics as G. Deleuze's innovative contribution to contemporary political philosophy. This objective will lead us to inspect the concept of power that Deleuze borrowed from Foucault and extended in order to assign to it an ontological adequacy. The concept of power opens access to another important element of the Deleuzean political philosophy, that is, the study of the historical diagrams of the power in the so-called discipline and control societies. With the combined dynamical diagram of both, we become aware of the portrait Deleuze draws for the democracy in contemporary societies. Digging into the Deleuzean ontopolitics, we will devote ourselves to the concepts of majority, minority and minor-becoming. It is in this point that the meeting between Deleuze's ontoplitics and Ch. Sanders Peirce's mathematical ontology becomes sound. It happens that Deleuze's ontopolitical concepts, besides their bond to an ontology of the power, receive also a mathematical treatment related to certain arithmetical (denumerable and nondenumerable) and geometrical notions (lines). The majorities and minorities are denumerable sets which are crossed by nondenumerable becomings. This step done, we will reach the stand point of the present paper, where we carry out initial approach with regard to an image for the concepts of majority and minority on the basis of Peirce's theory of collections and multitudes, mostly envisaging the mathematical ontology included in it. Accordingly, the main operation to be accomplished is that the Deleuzean distinction between the denumerable majorities/minorities and the nondenumerable minobecoming may be mapped out in terms of discrete collections called enumerable, denumerable and abnumerable or postnumerable, in compliance with Peirce's terminology.

KEYWORDS - Deleuze. Peirce. Ontopolitics. History. Multitude.

\section{Introdução}

Podemos dizer que a principal contribuição do pensamento de Deleuze à filosofia política foi o desenvolvimento da ontopolítica, isto é, o domínio em que certos problemas de alcance ontológico se desdobram em questões políticas ou emitem conceitos renovados acerca de problemas clássicos da filosofia política. Zizek (2008, p. 35) afirma que seria necessário definir ou redefinir uma política deleuzeana, tendo em vista que Deleuze, até sua associação com Guattari, teria sido um filósofo aristocrático, indiferente 
à política. Além disso, essa política deleuzeana deveria, segundo ainda Zizek, ser depurada do deleuzianismo ou do Deleuze guattarizado ("le Deleuze guattarisé") em política, tendência que hoje demarcaria a recepção da obra de Deleuze e sua associação aos movimentos sóciopolíticos contemporâneos. Em que pese essa ressalva, preferimos aqui afirmar que toda a obra de Deleuze é marcada por teses ontopolíticas e que, por isso, é insuficiente ou impreciso afirmar que até certo momento ele não se interessara pela política e, quando o fez, acabara por facilitar certa corrupção de sua filosofia inicial. Ao contrário, afirmamos que o veio da filosofia política de Deleuze, antes, durante e depois de sua associação com Guattari, está na proposição de um pensamento ontopolítico, de acordo com Cardoso Jr. (1999).

No mesmo diapasão, podemos dizer que a ontopolítica de Deleuze, conforme ficará patente ao longo do texto, responde à questão central formulada por Mengue (2003, p. 16), interrogando o suposto "paradoxo central de toda a filosofia política deleuzeana: como uma filosofia do múltiplo pode ser contra a democracia que é pluralista por excelência?" Em primeiro lugar, não cremos que haja na filosofia de Deleuze o paradoxo descrito, pois não podemos entender que a crítica ontopolítica da democracia tenha um respaldo antidemocrático. Em segundo lugar, salvar Deleuze do suposto paradoxo, ainda segundo Mengue (Ibid., p. 18-20, 192-195), seria reler sua filosofia política, procurando restabelecer os conceitos que ainda trazem consigo a lembrança da modernidade historicista ou, ainda, criar novos conceitos que correspondam aos aspectos positivos do jogo democrático na pós-modernidade, dessa forma atualizando uma potencialidade enrustida no pensamento deleuzeano. Quanto a esse aspecto, veremos que, no interior do universo conceitual deleuzeano, basta reunir seus conceitos ontopolíticos e sua descrição a respeito da sociedade de controle para daí extrair certas ilações a respeito da hibridação entre capitalismo e democracia dentro do que se convenciona chamar pós-modernidade. Em apoio a essa hipótese, temos o testemunho de Thoburn, para quem Badiou erra ao afirmar que Deleuze recairia em um "modelo de crítica politicamente vazio" (THOBURN, 2003, p. 5) quando propõe uma "política do capital" (Id., Ibid.). Concordamos com esse comentador quando ele declara que "política para Deleuze, então, é ao mesmo tempo um processo de invenção da vida e um engajamento com relações especificamente capitalistas" (Ibid., p. 6; ver também ANTONIOLI, 2003, p. 166-178). Em complemento, Purdom (1997, p. 117) afirma que há conceitos deleuzeanos suficientes para explicar de que forma, na política pós-moderna, "o poder do Estado é efetivamente usurpado pelo poder do capital".

Tendo em vista as ressalvas e delimitações da literatura especializada 
resumidas acima, podemos dizer que a chamada ontopolítica de Deleuze, de fato, como assevera Mengue (2003, p. 206), mostra que o "ensinamento incontestável, e o melhor, do pensamento deleuzeano, [...], não é político", no sentido, cremos nós, de que Deleuze não estudou os regimes políticos, nem particularmente a democracia, como Platão e Aristóteles, não se interessou pela cidadania, pelo Estado, nem pelos direitos universais do homem, como os filósofos políticos modernos. Ele esteve interessado, isto sim, pelo modo como as relações de poder, em nossa sociedade, criam dispositivos historicamente determinados, que têm como objeto o corpo e agem sobre ele a fim de extrair determinadas funções. Sendo assim, somos autorizados a afirmar que a ontopolítica de Deleuze, muito próximo de Foucault, neste caso, se ocupa das relações de poder. No entanto, falando dessa forma, recaímos em um conceito clássico da filosofia política, o conceito de poder. Então, qual a novidade do pensamento político deleuzeano? É certamente necessário, e o faremos mais adiante, definir o que Deleuze quer dizer com poder. Por ora, vale assinalar os caracteres básicos que tal conceito deve observar para fazer parte do que passamos a denominar ontopolítica deleuzeana:

a) não há uma definição geral de poder, por isso é mais apropriado falar em relações de poder, ao invés de substantivar o termo, isto porque a sua eficácia e a concretude do poder dependem de modos históricos sempre determinados;

b) as relações de poder têm como o objeto o corpo, mas elas não se aplicam simplesmente ao corpo, elas produzem algo e essa produtividade se atualiza no corpo.

Sendo assim, basicamente, devemos partir do princípio de que a vida política envolve relações de poder, mesmo que seja democrática, e por isso têm uma vigência histórica. Ao mesmo tempo, essas relações não são apenas gestoras de indivíduos, mas produzem em seus corpos algo, elas moldam esses corpos e, por isso, usufruem de um caráter ontológico, isto é, produtivo quanto a esses indivíduos.

O poder tenta moldar os corpos; é sua produtividade. Mas, essa é apenas uma parte do programa da aqui chamada ontopolítica deleuzeana. A questão é que essas relações de poder não estão além dos indivíduos que elas conformam; elas são imanentes ao que nos indivíduos se pode chamar de liberdade. Portanto, há uma zona de interseção entre poder e liberdade, de modo que se pode dizer que só existem relações de poder, no sentido ontopolítico deleuzeano, desde que se possa supor a relação entre indivíduos livres, que julgam e negociam aquilo que pode ser capturado por mecanismos de poder institucionais e o que pode ser preservado ou, mesmo, resistir a esses mecanismos, permanecendo virtualmente reservado como fonte de relações de poder não dadas. Em Deleuze, 
portanto, trata-se de uma política ontológica que passa pelos mecanismos sólidos de poder, pelas instâncias de representação institucionais e pelas normas do direito, enfim, pelas instâncias do Estado, mas não tem a este como sede, de modo que se pode afirmar a justo título que tais relações são mais líquidas do que o Estado gostaria.

Sendo assim, dar melhor contorno ao conceito deleuzeano de poder nos parece uma via segura para se falar em filosofia política deleuzeana e para apreciar o que Deleuze entende por democracia, maioria e minoria e representação política, na clave da ontopolítica.

\section{Poder e política para Deleuze: os diagramas históricos das sociedades disciplinar e de controle}

\subsection{Conceito foucaultiano-deleuzeano de poder}

Foucault chama atenção para o fato de que devemos nos livrar de uma concepção jurídica do poder, isto é, de que o poder se exerce como força sobre um objeto para conformá-lo à vontade de quem o detém ou à finalidade de uma instituição. Para Foucault, o poder constitui a realidade, é uma relação microfísica (FOUCAULT, 2001, passim). Em História da Sexualidade, vol. 1 (FOUCAULT, 2001), temos um resumo sobre seu conceito de poder. Da mesma forma, Deleuze, no livro chamado Foucault (1986), procura sistematizar este conceito, de modo que podemos dizer que há um conceito foucaultiano de poder em Deleuze ou que Deleuze retira da filosofia de Foucault certos problemas políticos que ensejam seu conceito próprio de poder.

Podemos começar pela concepção que o próprio Foucault tinha de luta política. Ele somente acreditava na prática política que tinha como foco lutas locais e específicas, cujas relações não poderiam mais vir de um processo de centralização nem de totalização. Com efeito, para ele, era muito mais importante a luta como "demonstração de existência" do que como ideologia política. Por isso, ele que viveu, na Tunísia, os primeiros meses de 1968 e, e tendo lá presenciado a revolta dos estudantes, compara este evento com o maio de 1968, em Paris. Na Tunísia, a ideologia, diz Foucault, vem a reboque da intensidade que marca as lutas locais, ao passo que, em Paris, a ideologia e a teoria ficaram hipertrofiadas com relação às práticas (ERIBON, 1990, p. 182).

Vamos, então, nos valer dessa ideia básica para nos aproximar do poder. Segundo Foucault e Deleuze, o poder não se concentra, não se centraliza, nem se totaliza. Ele faz e se desfaz em focos. Eles desafiam a ideia esquerdista de que o poder seria propriedade de uma classe que o conquista. O poder não é uma propriedade, ele não está concentrado em 
uma sede, pois é uma estratégia. O poder é uma questão de exercício, não de posse.

Em segundo lugar, Foucault e Deleuze desvalorizam a ideia de que o poder seria relativo ao Estado, sendo este seu detentor, de modo que este seria sua sede. Mas, é o contrário que acontece, o Estado é o efeito de uma multiplicidade de focos de poder. Estes são difusos, pois, somente em condições especiais, esses focos se reúnem tomando dimensões abrangentes como as de um Estado. O poder é constituído por relações, por isso não dispõe de um lugar privilegiado como sua fonte. Quando Foucault e Deleuze se referem a "lutas locais", eles não querem dizer que o poder tenha localização. O poder "é local porque nunca é global, mas ele não é localizável porque é difuso" (DELEUZE, 1986, p. 34).

Eles também recusam uma ideia de poder que seja tomada como atributo, que daria qualidade àqueles que o possuem (os dominantes), distinguindo-os daqueles sobre os quais o poder é aplicado (dominados). Para eles, o poder é uma relação que passa tanto por aqueles que dominam quanto pelos são dominados. A abordagem de Foucault/ Deleuze, portanto, rejeita os conceitos de "ideologia" e "repressão". A noção de ideologia coloca-se como o contrário daquilo que seria verdade. Mas, segundo esses autores, não interessa separar o que num discurso é verdadeiro e o que não o é. A noção de repressão, por sua vez, é mais difícil de desvincular da ideia de poder, porque a repressão parece ser logicamente um dos efeitos do poder, talvez o mais marcante entre eles, Foucault e Deleuze. No entanto, ressalvam que definir o caráter do poder pela repressão seria ter dele uma concepção jurídica, onde o fundamento seria a força de proibição. Argumentam que se a função do poder fosse dizer não, forçar, interditar, ele dificilmente seria obedecido. O que acontece com o poder, como assinalamos, é que ele é uma relação, é uma rede produtiva que se estabelece na sociedade através de mecanismos cuja vigência é histórica. Por isso, é importante sempre perguntar em que diagrama de poder está-se inserido, pois não há um conceito universal de poder, de maneira que falar em democracia, em nosso tempo, significa definir o funcionamento de dois diagramas de poder dos quais fazemos parte: as sociedade disciplinar e de controle.

\subsection{Diagrama do poder na sociedade de disciplina/controle}

Toda sociedade impõe um controle social. Mas é exatamente esse controle que varia historicamente, devido às tecnologias políticas que caracterizam as relações de poder. O principal elemento de incidência das relações de poder é o corpo; este atualiza essas relações. $\mathrm{Na}$ sociedade disciplinar (final do século XVIII, séculos XIX e XX), conforme descrito por Foucault, em Vigiar e Punir, o corpo é um objeto de análise 
e é fragmentado, a fim de que a disciplina possa transformá-lo em um "corpo útil". Através de certas técnicas que se aplicam ao corpo, o ser humano é visado como um objeto que pode ser modelado. Foucault dá o exemplo dos exercícios militares, onde a coordenação dos movimentos dos soldados visa destituí-los de toda dimensão subjetiva, de modo que cada um deles possa estar ligado por operações formalizadas. Trata-se de uma organização do espaço - o espaço disciplinar - mas também do tempo, pois a ideia é que uma função disciplinar (operações formalizadas) molde os corpos em tempo contínuo dentro de cada espaço disciplinar. $\mathrm{E}$, quando o indivíduo sai de um espaço para o outro, ou seja, quando ele vai ser moldado segundo outra função, a operação exercida sobre o corpo no espaço anterior serve como preparo para a nova função.

Família, Escola, Exército, Fábrica, Hospital, Prisão... a sociedade disciplinar se organiza de acordo com a contiguidade de vários espaços disciplinares, onde funções, embora diferentes entre si quanto a seu objetivo, se interconectam no sentido de que obedecem ao mesmo diagrama ou organização. Desta forma, o ideal da sociedade disciplinar é maximizar o exercício da função em cada espaço para que as várias funções disciplinares se encadeiem sem lacunas. Ela também precisa aumentar os espaços disciplinares, a fim de que o deslocamento dos indivíduos entre os vários espaços não interrompa a continuidade da modelação. Em determinado sentido, pode-se dizer que a disciplina controla os corpos para produzir indivíduos. Eis a produtividade do poder disciplinar: produção de individualidade através de modelagem dos corpos nos espaços disciplinares. Quando a função é educar, a matéria são os escolares; quando é castigar, a matéria são os prisioneiros, e assim por diante.

Deste modo, a tecnologia disciplinar parte da ideia de que os indivíduos têm entre si uma igualdade formal. O exame, enquanto procedimento da tecnologia disciplinar, transforma o indivíduo em objeto de conhecimento. Os detalhes da vida cotidiana tornam-se temas de pesquisa, através de documentação minuciosa. Para Foucault, quanto a este aspecto, há uma ligação importante entre as ciências humanas e os procedimentos disciplinares. De fato, um espaço disciplinar é, ao mesmo tempo, um lugar de aplicação de tecnologia disciplinar e um laboratório onde um saber é produzido de modo bruto, isto é, como dados a serem organizados e formalizados em procedimentos, teorias, sistemas, etc. Sendo assim, pelo jogo dessa quantificação, dessa circulação dos adiantamentos e das dívidas, graças ao cálculo permanente das notas a mais ou a menos, os aparelhos disciplinares hierarquizam, numa relação mútua, os "bons" e os "maus" indivíduos. Através dessa microeconomia de uma penalidade perpétua, opera-se uma diferenciação que não é a dos 
atos, mas dos próprios indivíduos, de sua natureza, de suas virtualidades, de seu nível ou valor (FOUCAULT, 1999, p. 151).

A sociedade disciplinar é formada por vários espaços disciplinares, cada um deles tomando o corpo como objeto da qual extrai uma determinada função disciplinar. Devido à articulação em rede dos espaços disciplinares, Foucault e Deleuze afirmam que existe um "diagrama" da sociedade disciplinar. Trata-se de um esquema de seu funcionamento que explica, em cada caso, como o corpo é submetido a uma tecnologia de poder. $\mathrm{O}$ "diagrama de um mecanismo de poder" porque resume seu "modelo generalizável de funcionamento", sendo uma "maneira de definir as relações de poder com a vida cotidiana dos homens", que se destaca de "qualquer uso político" para se tornar uma "figura da tecnologia política" (DELEUZE, 1986). As aplicações desse diagrama são múltiplas: corrigir prisioneiros, cuidar dos doentes, instruir escolares, guardar loucos, fiscalizar operários. O conceito de diagrama em Deleuze, aqui destacado na alçada política, também é utilizado em sua estética, mas sua origem é matemático-semiótica, e possui ligações com o conceito de mesmo nome proposto por Peirce (AMIEVA, 2007).

O diagrama disciplinar caracteriza-se, portanto, por espaços fechados, não muito extensos, e por se aplicar a uma multiplicidade relativamente pouco numerosa de indivíduos. A grande lacuna da sociedade disciplinar era a questão dos espaços interdisciplinares. Procura-se coordenar todas as funções disciplinares, mas sempre restavam lacunas à disciplinarização. Por quê?

Os saberes e os poderes de todos os tempos procuram capturar os corpos e os indivíduos se beneficiam dessas capturas que os colocam em redes que promovem a vida coletiva. Mas, como dissemos acima, os corpos guardam sempre uma reserva de desvio e escape com relação aos dispositivos, perfazendo uma história da resistência relativa à vida, pois "o ponto mais intenso das vidas, onde se concentra sua energia, fica exatamente ali onde elas se chocam com o poder, se debatem com ele, tentam utilizar suas forças e escapar de suas armadilhas" (FOCAULT, 1977, apud DELEUZE, 1986, p. 101). O que acontece, então, é que, por mais disciplinados que sejam, os corpos encontravam como ponto de fuga os espaços de intervalo entre os lugares de disciplinarização. Os espaços disciplinares não eram eficazes se não fossem pouco extensos. Em espaço aberto, a disciplina não alcançava os corpos. Esse era o ponto cego da sociedade disciplinar. Foucault descobrira pontos de resistência difusos, na maioria das vezes imperceptíveis para uma percepção disciplinar (FOUCAULT, 1985, p. 91-92).

Em vista do relativo fracasso das disciplinas, a partir de meados do século XX, os dispositivos de captura dos corpos começam a funcionar 
de acordo com uma nova dinâmica. Os indivíduos passam a ser moldados em espaço aberto. As subjetividades não se reduzem mais à individualidade, ao centro de um "eu". Ao contrário, as subjetividades são formadas por feixes de fluxos que se combinam ou se afastam em um movimento acelerado. Os modos de moldagem dos corpos não mais se confinam aos espaços disciplinares, submetendo os indivíduos a uma vigilância generalizada - essas novas práticas de compor subjetividades caracterizam o que Deleuze convencionou chamar de "sociedades de controle" (DELEUZE, 1990, p. 219-226).

Ao invés dos moldes de subjetividade baseados na identidade do indivíduo, teremos uma subjetividade em modulação contínua. Não precisamos mais estar em casa para nos sentirmos filhos ou na escola para aprendermos como aluno. Por um lado, somos filhos e alunos em qualquer parte, pois sermos estes ou aqueles são fluxos portáveis e montáveis. Por outro lado, temos uma margem de escolha, pois como a subjetividade é apenas o ponto de cruzamento de diversos fluxos, então, podemos deixar de ser filhos ou alunos quando ser um ou outro satura. Então, vivemos quanto à nova sociedade de controle uma situação paradoxal. Os lugares que, na época da disciplina, constituíam-se enquanto espaço de fuga e de resistência, agora são o lugar do controle. Parece que não adianta ser um nômade com relação aos espaços disciplinares, já que a própria sociedade capitalista criou um dispositivo nômade que captura a subjetividade em movimento.

\section{Elementos da democracia segundo Deleuze}

\subsection{Maioria, minoria e devir-minoritário}

Agora que já delineamos os principais caracteres dos diagramas das relações que regem nossas sociedades, misto de disciplina e controle, podemos apresentar certos elementos que põem em funcionamento a democracia nessas sociedades, de acordo com Deleuze.

A busca pelo consenso e pela opinião, que são mecanismos políticos de votos, está igualmente envolvida por dispositivos de disciplina ou controle, conforme o caso, onde as subjetividades e as opiniões são moldadas. Portanto, em primeiro lugar, o que chamamos democracia, do ponto de vista deleuzeano, altera-se, quer os mecanismos de consenso sejam disciplinares ou de controle. Em segundo lugar, do ponto de vista da análise histórica, há que se atentar para o fato de que não existe uma democracia disciplinar ou de controle em estado puro, já que a vigência de uma ou de outra não prevalece e pode ser que vivamos uma democracia onde se forma um misto de disciplina e de controle; sem 
contar a variedade nacional dos casos considerados. Ao mesmo tempo, e basicamente, esses dispositivos onde estão envolvidos maiorias democráticas produzem necessariamente pontos de resistência e linhas de fuga, como vimos acima, ensejando o que Deleuze denominou devirminoritário. Ora, então, temos que a principal questão política deleuzeana é que o devir-minoritário faça parte da democracia, na medida em que ele pode ensejar resistências ou linhas de fuga aos dispositivos de captura das maiorias democráticas.

O princípio da democracia representativa é ilustrativo sobre a maneira pela qual se pode entender a lição política dos devires, colocando-se em suspenso as diferenças históricas e dos casos considerados, conforme ressalvamos anteriormente. Uma maioria é definida politicamente pela quantidade, maioria simples ou proporcional. Antes, porém, de ser caracterizada por uma expressão numérica, uma maioria é um padrão, um "Alguém", onde o senso comum aprisionou determinados caracteres e ao qual os indivíduos devem-se enquadrar através da exclusão ou submissão de outros caracteres, sendo que o conceito de senso comum, em Deleuze, tem uma alçada basicamente kantiana, segundo Gualandi (1998, p. 91-93), em relação ao qual não temos espaço para uma apresentação pormenorizada aqui. Contudo, como a base da maioria quantitativa é um padrão restrito, os indivíduos componentes dessa maioria tornam-se, por uma razão ou outra, ao longo do processo democrático, mal acomodados a ela, sempre que alguns desses caracteres se desestabilizem ou não caibam no padrão estabelecido. Quer dizer, toda maioria freme com a agitação que esses caracteres aprisionados fervilham e impõem à estabilidade do padrão. Mais à frente, a ideia grosseira de que uma maioria é um padrão instável - ideia, aliás, corriqueira - será esmiuçada e especificada com a ajuda de conceitos matemáticos, já que os padrões que são as maiorias funcionam de acordo com o que se denomina coleções, cujos elementos são, por sua vez, multidões, de indivíduos quaisquer (elementos, não necessariamente pessoas ou, no caso, cidadãos politicamente ativos), os quais, devido a certas relações que regem as coleções, apresentam uma dinâmica que, se apropriadamente caracterizada, pode dar conta de descrever a dinâmica das democracias representativas atuais, conforme Deleuze a entende.

Na verdade, como mostra Deleuze e de acordo com Cardoso Jr. (1999), o poder de uma maioria somente se sustenta pelo senso comum, pois os indivíduos que compõem sua supremacia numérica a submetem a uma variação contínua, pois cada um, potencialmente, dentro do jogo democrático, se comporta e é visado como uma minoria que quer se libertar do jugo do padrão. Por isso, as minorias são muito mais numerosas que a maioria, pois aquelas detêm o segredo de sustentação desta 
última. As minorias são "multidões" cuja organização desestabiliza o consenso da maioria e sua ordem política. A esse respeito Hardt (1993) esclarece que "a multidão permanece contingente na medida em que está sempre aberta para o antagonismo e o conflito, mas em sua dinâmica de incremento de poder, ela atinge um plano de consistência, tem a capacidade de fazer da normatividade social o direito civil. A multidão é a multiplicidade que se torna poder" (p. 110); este mesmo autor acredita ter encontrado, em Deleuze, "algumas ferramentas para a constituição de uma democracia radical" (p. 119). Neste caso, sendo a minoria definida como elo definidor e/ou desestabilizador da maioria, então, ela não representa apenas a expressão numérica daqueles grupos que não se enquadram no padrão estabelecido pelo senso comum da maioria, mas, intensivamente, minorias são a respiração vital da maioria ("coleção enumerável"), ou seja, elas formam um "devir-minoritário" ("coleção abnumerável") que diz respeito a todos; até mesmo àqueles indivíduos que parecem encarnar o modelo de Alguém ("coleção denumerável") ${ }^{1}$ para a maioria e constróem sua variação em torno do padrão vigente. $O$ devir-minoritário, em outras palavras, é um princípio de transformação, um vir a ser das maiorias democráticas; enquanto a maioria representa apenas um estado determinado de aprisionamento de caracteres, criando a ilusão de sua universalidade ao colocar-se como representante de uma vontade, de um poder (GUATARI e ROLNIK, 1993).

Um devir-minoritário é um efeito dos encontros de indivíduos que caracterizam uma maioria e, como tal, a libera de sua relatividade numérica, posto que as relações são sempre exteriores aos indivíduos que formam a coleção das maiorias; as relações são exteriores no sentido de que as maiorias, como estamos vendo, são regradas pelas leis que regem minorias multitudinais. Por isso, conclui Deleuze, com propriedade, analisando um determinado veio político do teatro contemporâneo, "minoria designa aqui a potência de um devir, enquanto maioria designa o poder ou impotência de um estado, de uma situação"; as mesmas observações são válidas com respeito às imagens do cinema, pois através delas uma minoria pode passar pelo devir universal de um povo do futuro (DELEUZE e BENE, 1979, p. 129; 123-125; DELEUZE, 1983, p. 101; DELEUZE, 1985, p. 282-286; ver também DELEUZE e GUATTARI, 1980, 133-134; DELEUZE, 1990, p. 235). O devir, independente da matéria que ele venha a percorrer, instaura uma política acontecimental, multitudinal, e não uma política baseada no Estado reconhecido dos indivíduos num determinado tempo e espaço.

Essa terminologia das coleções ficará definida adiante, quando tratarmos da teoria peirceana das multidões. 
Para sermos fiéis às disposições apresentadas na introdução do presente artigo, podemos agora precisar que o devir-minoritário é o conceito-chave do que denominamos de ontopolítica deleuzeana. Tendo isso em vista, precisamos prosseguir, a fim de discutir outra hipótese que ficou para ser preenchida em nossas discussões, ou seja, a de que a ontopolítica que aqui estamos caracterizando apresenta uma dinâmica dada por conceitos políticos que podem ser apropriadamente entendidos como coleções de indivíduos, que funcionam de acordo com determinadas relações.

\subsection{Maiorias/minorias e conjuntos/relações}

Um devir é sempre uma questão de velocidade. Sempre se entra em um devir para experimentar que se é mais rápido do que uma maioria, para saber que esta última sempre chega depois, em seu esforço contínuo de deter os caracteres que dela querem escapar a todo custo. Ou, para apresentar o problema em termos aritméticos, como faz Deleuze, diz-se que a maioria forma entre seus elementos (minorias que se afastam mais ou menos da maioria) conjuntos ligados por uma relação axiomática e, por isso, são como números que podem ser contados e recombinados sempre que o conjunto e, portanto, o princípio axiomático fica ameaçado por uma minoria que está em ponto de ruptura com a maioria. Pode-se mesmo romper com a organização inicial e se entrar em uma nova axiomática que supostamente inclua e faça valer a representação de uma minoria, pois é uma verdade simples, também, que as democracias se esmeram na inclusão de minorias numéricas (ANTONIOLI, 2003, p. 172-175).

Já a minoria, do ponto de vista do devir-minoritário, é formada por elementos cujo único elo é a adição, lógica do "e"; por isso, eles formam "conjuntos fluídos", que não podem ser numerados, pois quando se tenta numerá-los, imediatamente sua natureza se transforma, isto é, as conexões entre seus elementos se distribuem de uma maneira completamente diversa, pois os encontros dos indivíduos que formam uma maioria sempre causam efeitos que não se detêm em realidade representacional. Por isso, eles não são axiomatizáveis, não servem a nenhum tipo de representatividade, embora exerçam sua ação política. Numa minoria, então, "o que caracteriza o não contável não é nem o conjunto nem os elementos; é antes a conexão, o "e", que se produz entre os elementos, entre os conjuntos, e que não pertence a nenhum dos dois, que lhes escapa e constitui uma linha de fuga", asseveram Deleuze e Guattari (1980, p. 587). Assim, por estar entre os conjuntos, por estabelecer relações em um meio que escapa à elementarização dos indivíduos, a minoria enquanto devir-minoritário é anterior, e, portanto, mais universal do que as relações numeráveis entre os elementos de um 
conjunto. De fato, de acordo com Mengue (2003, p. 74-75) e Thoburn (2003, p. 27-30), na política deleuzeana, há um primado ontológico e axiológico das linhas de fuga.

Como dizíamos acima, uma minoria, enquanto marcada pelo devir minoritário, como princípio da ontopolítica que rege a democracia deleuzeana, requer uma acontecimentalização da política, pela qual a dinâmica dos conjuntos axiomáticos da aritmética democrática é deslocada pela ideia de que tais conjuntos estão sob a égide de que seus elementos são regidos por relações que lhe são exteriores, isto é, por relações que não estão dadas pelos termos ou indivíduos que formam as multidões democráticas, atravessadas que são pelo devir-minoritário. Com efeito, minoria é uma "figura universal" que percorre, ou melhor, somente se deixa captar numa lógica cujas relações os conjuntos não podem dar conta, uma lógica do acontecimento, onde se desliza em "multiplicidades de fuga ou de fluxo", quando um grupo ou alguém "se torna todo mundo", pois "o próprio da minoria é fazer valer a potência do não contável. É a fórmula das multiplicidades", ou seja, onde "o devir e a multiplicidade são uma e a mesma coisa", pois na multiplicidade de devires, dizem Deleuze e Guattari a respeito do cinema, "os personagens e as formas valem apenas como transformações de uns nos outros" (DELEUZE e GUATTARI, 1980, p. 305, 588; ver também DELEUZE, 1985, p. 189). Sendo assim, o caráter dinâmico das coleções (maiorias e minorias), em multidões democráticas, somente pode ser apreendido corretamente, de acordo com o ontopolítica deleuzeana, quando seus movimentos são apreendidos dentro de entidades mais complexas chamadas multiplicidades (CARDOSO JR., 1996). Tendo em vista esses elementos, a ontopolítica inclui a chamada "política menor", segundo Thoburn (2003, p. 8):

Se maior e menor descrevem tendências na configuração da vida, eles têm seus correlatos na esfera humana da política. Política maior está baseada na identidade. A democracia moderna é o exemplo clássico. Democracia é um sistema de governança baseado em entidades juridicamente definidas como equivalentes umas às outras, definindo cidadãos como uma massa de pessoas. Política menor, por outro lado, começa com a condição fundamental ... de que um povo falta.

Os próprios conjuntos e as relações axiomatizáveis ou numeráveis entre os elementos de uma coleção democrática têm sua gênese garantida pelo elemento não contável das multiplicidades, pois o que diferencia definitivamente maioria e minoria não é a comparação numérica entre elas, mas uma relação interna ao número, que prova que o devirminoritário das minorias convida todas as maiorias a se desfazerem 
em multiplicidades, a fim de que elas se tornem mais universais do que supõe a generalidade ou abstração de um espaço e tempo dados extensivamente, que garantem o preenchimento dos valores de verdade de uma lógica axiomática ou dos conjuntos.

É importante seguirmos nessa linha de raciocínio, pois a importância da matemática para a filosofia de Deleuze tem sido negligenciada pelos comentadores e, na verdade, "os compromissos de Deleuze com a matemática confia na construção de linhagens alternativas na história da matemática, a fim de reconfigurar problemas filosóficos específicos e criar novos conceitos" (DUFFY, 2006, p. 1). Como estamos observando, a alçada matemática dos conceitos ontopolíticos de Deleuze conferemlhes um perfil inovador. Por isso, em seguida, a fim de reforçar os conceitos ontopolíticos de Deleuze, que, neste subtítulo, receberam uma caracterização aritmética em combinação com certas noções da teoria dos conjuntos, veremos uma caracterização das coleções democráticas tendo em vista certas noções geométricas. A dinâmica dessas coleções é melhor observada, segundo Deleuze (e Guattari), como complexos de linhas.

\subsection{Maioria e minoria em termos cartográficos: linhas}

Mas, o que acontece entre uma minoria e uma maioria, tendo em vista as definições acima?

Deleuze e Parnet mostram que uma boa maneira de analisar situações políticas é mapeá-las, realizando uma cartografia de suas linhas. A maioria é uma "linha dura" ou "molar", assim como o são nossos papéis individuais ou sociais - família, escola, caserna, fábrica, profissão, que são segmentos em que se subdivide essa linha. A linha segmentada é trabalhada por "linhas moles" ou "moleculares", sendo esta composta por devires que conduzem nossos papéis definidos a encontros não previstos em sua segmentaridade dura. Toda vida, todo papel social participa de intensidades não contidas numa biografia de família, numa memória da formação geral de um indivíduo ou grupo, no suposto consenso de uma maioria política.

Ambas as linhas - duras/segmentadas e moles/moleculares - são imanentes uma a outra. O mais importante para a realização da imanência, nessa cartografia, é que a linha molecular realiza importantes conexões de devires que não aparecem no nível da linha molar, ou seja, aquela atribui a esta última intensidades que sua segmentaridade dura não pode representar. Por exemplo, há uma maioria em um indivíduo ou em grupo social que é trabalhado imperceptivelmente por minorias, devires moleculares, mesmo que os segmentos que formam a maioria permaneçam inalterados. Apesar da relativa inércia molar, a linha 
molecular de uma minoria pode estar cruzando limiares que magnetizam intensivamente a segmentaridade da maioria, estabelecendo conexões não previstas (DELEUZE e PARNET, 1977, p. 151-152). Por isso, entre o molar e o molecular não há também uma oposição como coletivo/social e individual/pessoal; a molecularidade também se define por seu aspecto populacional ou multitudinário. Existem minorias em uma pessoa, assim como as minorias são as agitações moleculares das maiorias sociais e/ ou políticas.

Maioria e minoria atuam em planos diversos. A minoria não atua como um número, como um segmento; o que acontece em uma e em outra não pode ser avaliado pelo mesmo padrão de ocorrências. No entanto, como se explica que a oposição minoria-maioria se coloque do ponto de vista político, tanto que um dos objetivos da representação democrática é estabelecer em seus mecanismos um contrapeso para a expressão das minorias? Se num confronto direto a maioria se sobreporia às minorias, cabe criar dispositivos que garantam a sobrevivência destas últimas, assegurando-lhes representatividade apesar de sua menoridade quantitativa. Essas oposições são possíveis apenas como expressões da linha segmentada, onde a maioria se coloca. Deleuze e Parnet, aprofundando sua cartografia ou micropolítica, chamam a atenção para o fato de que a linha de segmentaridade possui três características (DELEUZE e PARNET, 1977, p. 155-157).

Em primeiro lugar, há as máquinas binárias que, no caso, criam oposição entre maioria e minoria, como se ambas fossem segmentos de uma mesma linha; a binarização do conflito é uma maneira de mitigar o caráter molecular das minorias. Naturalmente, a dicotomia entre minoria e maioria pode receber projeções de binarizações em outras oposições de segmentos, tornando complexos seus encontros; por exemplo, o problema que se coloca do ponto de vista da linha segmentada é: o que é maioria e minoria num modo de ser, numa sexualidade, numa família, entre duas classes sociais? Desta forma, a minoria é tomada como um segmento, onde o modo de expressão é a oposição.

Em segundo lugar, continuam Deleuze e Parnet, minoria e maioria como segmentos envolvem cada uma um dispositivo de poder que as codifica. Este é o padrão para todos os segmentos de uma dada linha dura, afinal somente na medida em que cada um deles constitui um centro de poder é que um pode estabelecer com o outro uma relação binária. O poder, portanto, não é central, não é um privilégio da maioria; ele se dissemina pela linha segmentada, tendo em vista o conceito foucaultdeleuzeano de poder, como vimos anteriormente. Além disso, há entre tais segmentos uma máquina abstrata de sobrecodificação que cria equivalências entre os códigos de segmentos; desta forma, por exemplo, 
a oposição entre minoria e maioria pode ser avaliada e fixada. Uma máquina abstrata, sobrecodificando todos os cortes entre segmentos, pode, enfim, traduzir e coordenar as dicotomias criadas pelas máquinas binárias e oferecendo-lhes um meio de conversibilidade e compensação democráticas.

É através das máquinas de sobrecodificação, então, que o impasse minoria-maioria pode ser encaminhado por meio de uma solução que preserve a determinação de uma minoria em face de uma maioria; neste caso, estamos diante da efetivação da máquina abstrata, o que já caracteriza o aparelho de Estado como terceiro elemento da segmentaridade dura. O Estado é apenas a sobrecodificação efetiva de centros de poderes que dele não emanam. Mas, isso é apenas o que ocorre na linha de segmentaridade dura ou molar.

Na linha mole ou molecular não há segmentos, apenas limiares; tratase de uma linha não segmentada e não codificada, onde a relação entre seus elementos constituintes, que são os devires, dá-se, não através de binarizações que levam a uma sobrecodificação, mas entre ritmos. A linha molecular não anuncia apenas que o segmento dominante mudou ou que seria possível um terceiro termo que superasse a dualidade entre minoria e maioria. Pelo contrário, ela passa entre os segmentos, oferece-lhes um fluxo de descodificação, de modo que as máquinas que conduzem os devires são máquinas mutantes que desfazem as oposições molares. Neste caso, a minoria não é mais um segmento da linha molar, mas um fluxo (devir minoritário) que faz tanto a maioria quanto a minoria segmentarizadas fugirem de seus códigos e, portanto, de seus dispositivos de poder.

Eis a definição molecular de um conceito renovado de minoria. Contudo, o fato de podermos observar a minoria sob o ponto de vista de duas linhas imanentes não explica ainda por que a minoria, no sentido molecular, constitui maioria como segmento da linha molar. Por que, afinal, minoria teria a precedência enquanto devir-minoritário?

Acontece que os fluxos de fuga proporcionados pela agitação da minoria não são uma passagem para fora do campo social, não são uma fuga do campo social. Ao contrário, as linhas moleculares são constitutivas do campo social, isto é, de suas segmentaridades duras. São as minorias em seus movimentos de fuga que traçam os devires e as fronteiras do político em um campo social, porque são elas que exigem imediatamente uma representação política, uma vez que participam de fluxos produtivos capitalistas (FERREYRA, 2010, p. 87-88).

Em seguida, como última parte e objetivo-maior do artigo em curso, procuraremos aprimorar a definição dos conceitos da ontopolítica deleuzeana, com respaldo nas imagens matemáticas que o próprio 
Deleuze fornece, tendo em vista o caráter multitudinário das coleções democráticas em sua dinâmica de maiorias-minorias. Veremos que o autor-chave, neste caso, será o matemático e filósofo Ch. Sanders Peirce. A progressão da embrionária ontologia matemática presente no pensamento de Deleuze é indicada como um importante trabalho que resta por ser feito (DELANDA, 2006, p. 247; DELANDA, 2002).

\section{Apontamentos para uma imagem matemática do devir-minoritátio}

\subsection{Multiplicidades, matemática e política: Peirce e Deleuze}

Observamos que a minoria, no sentido de um devir-minoritário, tendo em vista uma linha molecular, tinha um caráter multitudinário, isto é, o mesmo aparece em coleções chamadas multiplicidades. O mesmo se pode dizer de uma maioria, já que ela é uma coleção formada a partir do universo de coleções possíveis em uma sociedade democrática. Tais coleções são formadas por relações entre seus elementos, isto é, as multidões. Tendo em vista que Deleuze desenvolveu um conceito de multiplicidade ao longo de sua obra, nossa hipótese é que tais coleções - seja o caso de uma multiplicidade democrática - possuem um caráter operatório calcado em certa teoria das multidões. Por isso, vamos nos aproximar da obra matemática de C. S. Peirce, a fim de indicar a validade de se pensar o devir-minoritário em termos de multidões.

Gilles Deleuze (1925-1995) apóia-se basicamente em Charles Sanders Peirce (1839-1914), quando propõe o desenvolvimento de uma semiótica para o cinema. Peirce é reconhecido mundialmente como o criador de uma nova Semiótica, geralmente definida como a ciência dos signos. Mas, suas contribuições não se restringem apenas ao estudo e à classificação dos signos, pois eles desenvolveram sistemas abrangentes e complexos que reúnem os principais ramos da filosofia. O trabalho para interligar as duas filosofias ainda está para ser feito.

Há algumas conexões que interligam Peirce a Deleuze na filosofia contemporânea (CARDOSO Jr., 2006). De fato, o contato entre ambos constitui uma tendência de longa duração que percorre os 29 livros de Deleuze e atualiza o empirismo e o pragmatismo deleuzeanos. Deleuze dedicou seu primeiro livro, Empirismo e Subjetividade (1953), ao pensamento de Hume, num período em que a maior parte da filosofia francesa se convertia à Fenomenologia ou se voltava para o Estruturalismo. É por isso que o contato de Deleuze com Peirce, que acontece somente na década de 1980, nos livros acerca do cinema do primeiro, Imagem-movimento (1983) e Imagem-tempo (1985), não é acidental nem oportunista. 
O principal elemento da filosofia peirceana é o conceito de continuidade e podemos adotá-lo como ponto de partida para o tratamento das questões aqui em pauta. O referido conceito, em Peirce, tem duas partes: o contínuo imperfeito e o contínuo perfeito. O contínuo imperfeito é composto por coleções discretas; enquanto o perfeito por multiplicidades ditas contínuas. Um aspecto que se destaca na obra de Peirce é o fato de ser ele um filósofo que parte da Matemática e a mantém ao longo de sua obra como um de seus principais instrumentos de pensamento, de modo que se pode dizer que ele desenvolveu uma ontologia para a Matemática (MOORE, 2010, p. 6). Consequentemente, ele confere às coleções e multiplicidades um tratamento matemático próprio, acompanhado de ilações ontológicas inovadoras na história da Filosofia. Em primeiro lugar, as coleções discretas são assim denominadas por serem coleções de elementos com grau diverso de individuação. Em segundo lugar, Peirce define as multiplicidades contínuas, cujos elementos não são distintos individualmente. As multiplicidades discretas são, por ele, tratadas através de uma Teoria dos Números, por serem compostas por coleções cujas relações entre seus elementos formam conjuntos multitudinais (coleções "numeráveis", "inenumeráveis", "denumeráveis e "abnumeráveis") (PEIRCE, 1933, v. 3, § 631 e PEIRCE, 1976, v. 3, § 52). O centro da teoria peirceana das multiplicidades, nesse caso, enseja uma discussão em torno dos números cardinais, em dissensão para com a tese de Cantor, segundo a qual multidões transfinitas de cardinais definiriam uma verdadeira continuidade. Por sua vez, as multiplicidades contínuas são abordadas através de uma Geometria Tópica, a qual se baseia em propriedades que definem conjuntos multidimensionais ("coleções supermultitudinais"; "multiplicidade multidimensional" ou "continuum de continua"; e "continuum original"). A tópica peirceana apóia-se diretamente na Geometria de Riemann e nos Números de Listing, que não só procuram definir as multiplicidades contínuas, como também a vida da continuidade nelas, em termos de singularidades, transformações dimensionais e pontos de descontinuidade (HAVENEL, 2010).

A teoria das multiplicidades em Deleuze não recebe o estrito tratamento matemático como em Peirce. No entanto, ele a define em função de problemas da Filosofia da Matemática que se aproximam daqueles estabelecidos por Peirce. O estatuto das multiplicidades em ambos se baseia principalmente no estatuto do cálculo diferencial em Leibniz e na geometria multidimensional de Riemman, tendo em vista o modelo matemático que, segundo Deleuze, estabelece, em parte, uma teoria das multiplicidades. Em parte, porque, em Deleuze, o problema ontológico das multiplicidades vem a primeiro plano, principalmente com Husserl e Bergson (CARDOSO JR., 1996). Deleuze não demonstra conhecer 
os estudos dedicados às multiplicidades por Peirce, embora ambos tenham como patrono o físico-matemático Riemann. Quanto a este ponto, podemos dizer que as multiplicidades ou coleções discretas definidas por Peirce trazem novos elementos para o tratamento da teoria deleuzeana das multiplicidades; além disso, Deleuze, assim como Peirce, é um tanto avesso à solução trazida por Cantor para o problema da continuidade. Passemos em revista a teoria deleuzeana das multiplicidades.

Deleuze faz o recenseamento dos usos da teoria das multiplicidades por parte de alguns matemáticos, físicos, filósofos, sociólogos e antropólogos, por motivos imediatamente relacionados ao exercício de suas respectivas disciplinas. Ele acredita que esses estudiosos fornecem um conceito de multiplicidade que precisa ser definitivamente incorporado à filosofia e a, este respeito, as declarações de Deleuze são enfáticas: "concebo a filosofia como uma lógica das multiplicidades" (DELEUZE, 1990, p. 201) e "a filosofia é a teoria das multiplicidades" (DELEUZE, 1996, p. 179). Denomina, em termos bergsonianos, de multiplicidade virtual aquela marcada pela duração contínua e de multiplicidade atual aquela marcada por uma pluralidade de tempos, cada um correspondendo a uma linha de atualização, sendo que cada tempo atual é um grau coexistente na unidade da duração, sendo o espaço, justamente, o elemento que acolhe as variações da duração. O conceito deleuzeano de multiplicidade somente se estabeleceria, de modo original, quando as multiplicidades virtual e atual fossem imanentes uma a outra, sendo o princípio dessa imanência uma multiplicidade substantiva, pois o que falta à filosofia "é uma teoria das multiplicidades por elas mesmas, no ponto em que o múltiplo passa ao estado de substantivo..." (DELEUZE, 1995, p. 8).

Então, os termos da troca entre Deleuze e Peirce quanto à teoria das coleções e das multiplicidades se resumem ao seguinte: o tratamento matemático de Peirce pode contribuir para a definição e discussão ontológicas das multiplicidades deleuzeanas, particularmente quanto às multiplicidades atuais. Sigamos em direção aos conceitos, a fim de realçar sua alçada ontopolítica.

\subsection{Multidões, coleções, maiorias e minorias}

\section{O que é uma multidão?}

Multidão é um conjunto de números em uma coleção independentemente de sua ordem ou arranjo. Por exemplo, $[A, B, C]$ e [C, B, A] são as mesmas coleções porque elas têm a mesma multidão, embora diversamente organizadas (PEIRCE, 1935, v. 4, §§ 647-651). "Por uma coleção", diz Peirce, "eu quero dizer qualquer coisa que é u'd por tudo que tem uma certa qualidade ou descrição geral, e por nada mais" (Ibid., § 170). Se qualquer $\mathrm{A}$ é uma unidade ou indivíduo de $\mathrm{B}$, então $\mathrm{A}$ é u de $\mathrm{B}$ (A é 
unidade de B) ou, reciprocamente, "B é u'd por A" (Ibid.), ou seja, B é um todo que tem $\mathrm{A}$ como sua unidade. Mas B só é uma coleção se partilha com A certa qualidade comum, de modo que se A tem alguma qualidade a, então B é u'd por A através de determinada qualidade $a$.

As unidades de uma coleção não pertencem necessariamente ao mesmo "universo de discurso" (PEIRCE, 1935, v. 4, § 171), de forma que tipos diferentes de unidades constituintes são possíveis; principalmente, há unidades em uma coleção que possuem identidade distinta, enquanto outras não a possuem, na medida em que se comportam como meras potencialidades. As coleções com unidades que detêm identidade individual são "coleções discretas" (Ibid., § 175); enquanto as coleções onde figuram unidades sem identidade distinta "encarnam condições de possibilidade, e o possível é geral e continuidade e generalidade são dois nomes para a mesma ausência de distinção entre indivíduos" (Ibid., § 172). Além disso, "o possível é inexaurível em qualquer multidão atual" (PEIRCE, 1976, v. 2, § 517). Comparativamente, pode-se dizer que as coleções discretas são maiores ou menores, mas se a coleção não corresponde a nenhuma existência extensivamente determinável, isto é, cujas unidades tenham identidade individual, então ela cessa de ser uma coleção discreta para formar uma multiplicidade contínua, isto é, cujas unidades não têm distinção individual. Do ponto de vista deleuzeano, essa distinção seria suficiente para caracterizar o atributo das maiorias como contável e o do devir-minoritário como não contável, de acordo com os termos que indicamos acima. No entanto, Deleuze adverte que em todo atual, em todo elemento discreto dotado de identidade, permanece a instância do virtual como problemática, quer dizer, todo contável inclui algo não contável. Tendo em vista essa perspectiva aberta por Deleuze, podemos aproximar suas multiplicidades das coleções peirceanas discretas que são habitadas por elementos não individuais.

Justamente, a par desses fundamentos peirceanos da teoria das coleções e multidões, podemos fazer uma primeira aproximação com os conceitos de maioria, minoria e devir-minoritário anteriormente discutidos. As maiorias formam coleções discretas, posto que suas unidades, os indivíduos em uma democracia representativa, mantêm identidade distinta. Já o devir-minoritário formaria uma multiplicidade contínua onde as unidades não possuem identidade individual, posto que, justamente na qualidade de devires, são passagens de estados, de combinações e recombinações, de ritmos e encontros, que se desprendem da compleição discreta das maiorias.

Porém, essas associações são preliminares e francamente insuficientes, pois se a matemática peirceana é de fato útil quanto à qualificação de uma democracia deleuzeana, então ela precisa explicar de que modo se 
dá a gênese da maioria em uma coleção discreta de indivíduos. Da mesma forma, precisamos saber como funciona a multiplicidade contínua do devir-minoritário e qual seu comportamento com relação à coleção discreta das maiorias. É que as coleções discretas não estão definitivamente separadas das multiplicidades contínuas, como sugere a separação deleuzeana entre contável e não contável, pois um tipo específico de coleção discreta abriga unidades, que, embora individualmente distintas, o são apenas vagamente, como se fossem a premonição ou a memória das multiplicidades contínuas. Neste caso, temos uma precisão maior acerca de como, segundo Deleuze, a instância virtual das multiplicidades insiste como problema em coleções discretas ou multiplicidades atuais. Em outras palavras, esse tipo especial de coleção - determinada, mas menos definida - vive dentro de outras coleções discretas. De certa forma, essa coextensão entre elas se explica como um devir-minoritário; não só habita, como é a respiração das maiorias, como dissemos antes.

$\mathrm{Na}$ verdade, a fronteira entre coleções discretas e multiplicidades contínuas é mais difícil de traçar do que fizemos parecer na primeira abordagem, por isso certa precisão terminológica e conceitual se faz necessária, como alertamos. Há coleções discretas, por um lado, que incluem unidades sem identidade individual misturadas com outras individualmente distintas; por outro lado, há coleções discretas que só possuem unidades sem identidade assinalável. A tarefa mais complexa e estimulante sobre a teoria das multidões de Peirce será o estabelecimento destas progressões entre coleções discretas, pois isso envolve essencialmente o problema das relações que geram e regram as multidões, tendo em vista o caso vertente da democracia.

As coleções discretas são discriminadas segundo suas regras matemáticas de formação, de acordo com a terminologia peirceana, em: "enumerável", "denumerável", "abnumeral ou pós-numerável", visto que discreto significa que as unidades da coleção possuem identidade, mesmo que esta seja apenas genérica ou aproximadamente designada (CARDOSO JR., 2012, p. 25). Neste ponto, vale fazer certas considerações terminológicas que contêm ecos conceituais tendo em vista a teoria peirceana das coleções em sua associação com a ontopolítica deleuzeana. Acontece que Deleuze utiliza apenas dois termos para diferenciar coleções discretas e multiplicidades contínuas, ou seja, aquelas são "contáveis" (denumerable) e estas "não contáveis" (nondenumerable) (THOBURN, 2003, p. 7). Peirce, no entanto, como acabamos de indicar, apresenta coleções enumeráveis ou contáveis (enumerable) e denumeráveis ou não contáveis (denumerable) como dois tipos, entre outros, de coleções discretas. Isso significa que a matemática ontológica de Peirce mostra que entre o discreto e o contínuo há mais gradações 
do que supõe a correta, mas pouco detalhada, oposição entre contável e não contável. Devido a esse detalhamento, decidimos manter a tradução literal dos termos, ou seja, enumeráveis (enumerable) e denumeráveis (denumerable), ao invés de falar em coleções contáveis (dénombrables) e não contáveis (non dénombrables), conforme Deleuze. Além disso, a precisão terminológica em questão indica em que sentido específico a teoria peirceana das multidões pode contribuir para o aprimoramento conceitual da ontopolítica deleuzeana. Então, vamos definir cada uma das coleções denominadas acima, tendo em vista as relações que regem as suas multidões ou unidades.

\subsection{Enumerável, denumerável e abnumerável ou pós-numerável}

Quanto à coleção enumerável, ela poder ser descrita, principalmente, através de três características:

a) uma coleção enumerável partilha o mesmo caráter entre suas multidões a despeito de seus diversos arranjos;

b) a mais importante característica que uma coleção enumerável partilha com outra qualquer é a propriedade lógica que assegura "que se uma coleção enumerável for contada, o processo de contagem eventualmente chegará ao fim pela exaustão da coleção" (PEIRCE, 1935, v. 4, § 184; ver também PEIRCE, 1976, v. 3, § 49).

C) a parte de uma coleção enumerável não pode ser maior e tem de ser menor com relação ao todo do qual ela é parte.

Em uma democracia representativa, tendo em vista critérios estatísticos, uma população votante poderia ser dividida em tantas coleções enumeráveis capazes de agrupar seus indivíduos. Por exemplo, poderíamos ter uma coleção dos homens e mulheres brancas, dos homens e mulheres afros e dos homens e mulheres mestiços, se o critério de contagem fosse étnico. Da mesma forma, teríamos coleções enumeráveis segundo um critério religioso: votantes católicos, protestantes, evangélicos, seguidores de cultos afros, budistas, etc. Outras coleções poderiam ser formadas de acordo com quantas identidades fossem possíveis, a fim de definir as unidades constituintes discretas em uma coleção. Poderíamos dizer que uma maioria seria representada por uma dessas coleções definidas segundo critérios diversos, dado que, por exemplo, em um país onde a maioria numérica da população fosse branca e católica, então o padrão representativo seria dado por uma das coleções em face das demais possíveis. Mas, sabemos que para as complexas democracias multiculturais isso não é verdade, pois o alinhamento do voto transgride coleções discretas tão simples como as enumeráveis. Os afrodescendentes votam com brancos, os católicos com protestantes, etc. Sendo assim, precisamos entender como se formam maiorias concretamente nessas 
democracias multiculturais, pois, do ponto de vista matemático, de fato, o que nessas democracias se representa não é a parte que se sobrepõe ao todo como maioria.

Trata-se de uma maioria que, embora parcialmente formada a partir de coleções enumeráveis, é igual ao todo, na medida em que, como dizíamos anteriormente, ela forma uma entidade representativa através de Alguém, isto é, através da axiomatização das unidades de cada coleção enumerável considerada para sua composição. Quanto a esse tipo de maioria, é preciso entender o que Peirce denomina de coleção denumerável.

A coleção denumerável tem uma regra de formação simples, mostra Peirce. Ele pede que tomemos a coleção de todos os números inteiros, colocando-os em uma linha $(1,2,3, \ldots)$ e para cada número seja associado seu dobro $(2,4,6, \ldots)$. A coleção dos dobros é uma parte da coleção de partida, uma vez que cada número da segunda coleção, cada dobro, é um número inteiro (todos os números pares possíveis). Assim, o todo e a parte estariam numa relação de um para um, de modo que o todo e a parte seriam iguais. Essa nova situação escapa às propriedades que caracterizam as coleções numeráveis, por isso a igualdade entre a parte e o todo é chamada de "coleção denumerável" (PEIRCE, 1935, v. 4, § 188; ver também PEIRCE, 1976, v. 3, §§ 52-53).

Uma maioria democrática, numa sociedade complexa, forma-se como uma coleção denumerável, embora a regra de formação não seja tão simples quanto no exemplo anterior. Em todo caso, não se trata apenas de que a maioria, que é sempre uma parte, represente o todo, mas de que ela seja igual ao todo. A coleção que forma a maioria não é igual à dos votos de cada coleção enumerável de partida (brancos, negros, mestiços, etc.; protestantes, católicos, seguidores de religiões afros, budistas, etc.), mas uma coleção dessas unidades cuja regra de reunião não é étnica nem religiosa, já que os brancos podem votar em negros e os budistas em protestantes, etc. Uma regra de formação da maioria obedece, naturalmente, aos grupos de opinião que formam correntes dentro do conjunto de todos os votantes (enumeráveis). A coleção denumerável da maioria é um estado momentâneo das coleções enumeráveis que formam o universo de votantes em uma democracia representativa. Ela conjuga a estabilidade das unidades com plena identidade, nos grupos discretos, com combinações e recombinações passageiras que rompem essa identidade e a tornam vaga, de modo que toda maioria passa a ser entendida como tendendo para uma minoria qualquer que funciona como limite a ser incluído no movimento democrático. Nesse sentido é que a parte e o todo são iguais. A parte, a maioria, é uma transformação denumeral do todo de partida. De acordo com o retrato da sociedade 
de controle, acima traçado de acordo com o conceito deleuzeano, a inconstância das multidões em coleções denumeráveis permite entender de que maneira a democracia de massas funciona em tal sociedade, onde a opinião informatizada associa função econômica e função política dentro de um novo tipo de capitalismo (MENGUE, 2003, p. 48-51).

Obviamente, o espectro de variação denumeral da maioria depende das combinações e recombinações das unidades enumeráveis (identidades distintas). A maioria é uma flutuação em torno desses pontos discretos. Mas, o que acontece com os devires-minoritários, se é que eles podem ser tomados em coleções discretas?

Diversamente, seja dos arranjos enumeráveis seja dos denumerávis, coleções pós-numeráveis ou abnumeráveis possuem como sua principal característica a seguinte regra: que a partir de uma primeira unidade colocada na extremidade esquerda de uma linha horizontal, a próxima unidade para o lado direito teria as mesmas características, mas isso não seria verdade para todas as unidades que viriam depois. Esse tipo especial de coleção apresenta uma solução matemática para a disjunção inclusiva entre entidades potenciais (devir-minoritário) e entidades atuais ou discretas (maiorias e minorias) (CARDOSO JR., 2012, p. 33). Peirce chama a primeira coleção abnumeral de "coleção primoposnumeral" e a define assim:

Há algo que é verdadeiro para a primeira unidade e que se é verdadeiro para qualquer unidade é sempre verdadeiro para a próxima unidade à direita, que, no entanto, não é verdadeiro para todas as unidades (PEIRCE, 1935, v. 4, § 201).

Isso significa que na coleção primoposnumeral a regra de formação transgride a maioria, pois a primeira unidade e a seguinte à direita apresentam caráter denumerável, mas as multidões que formam essas duas primeiras unidades estão relacionadas de tal forma que a partir da terceira unidade não há características partilháveis. Estas outras unidades são abnumerais, pois se soltam das coleções denumeráveis e se tornam independentes. Elas não são mais a igualdade entre o todo e a parte como na maioria denumeral e, por isso, não flutuam em torno das unidades enumeráveis de partida. A coleção pós-numeral é o conjunto das regras de combinações e recombinações das unidades enumeráveis, quando essas regras são consideradas exteriores e anteriores às coleções denumeráveis e enumeráveis cujas unidades elas possam vir a relacionar. Então, ela é a coleção das relações por elas mesmas, configurando um conjunto fluido ou transformacional que envolve e é universal, no sentido de que é um princípio genético inclusivo com relação às coleções enumeráveis 
e denumeráveis. A coleção pós-numeral não possui mais elementos cuja identidade seja distinta, como para as coleções enumeráveis, e mistura unidades que possuem identidade individual discreta e outras com identidade individual vaga, como na coleção denumerável da maioria. Mas, o faz com muito menos significado das unidades que desfrutam de identidade individual. Ela explica como as entidades potenciais acabam por revolver as entidades atuais das coleções discretas anteriores. Ela inclui, então, o chamado devir-minoritário das maiorias e dasminorias.

Não tivemos a intenção, ao longo do presente artigo, de indicar a via para uma possível formalização dos conceitos políticos de maioria e minoria. Pelo contrário, tanto a ontopolítica de Deleuze, em sua alçada matemática, quanto a ontologia matemática de Peirce, como suas coleções e multidões, deixam claro que há um elemento bruto ou teimoso que resiste a uma axiomatização final e cuja existência, seja na forma dos devires e virtualidades deleuzeanos, seja na forma das potencialidades peirceanas, insiste problematizando as maiorias e minorias contáveis e submetidas aos planos de opinião em uma democracia moderna. Justamente, a ponte entre Deleuze e Peirce, por nós traçada, indica de que modo o não contável deleuzeano pode ser detalhado em termos de sua pertinência para a teoria das coleções peirceana. Na verdade, o elo entre ambos coloca-se como ponto de vista que enfrenta as objeções que Deleuze e Peirce, cada um por seu lado, têm recebido de importantes comentadores de suas obras críticas quanto à insuficiência matemática de suas respectivas ontologias. De fato, as entidades potenciais que garantem a riqueza das populações na teoria peirceana das coleções, conforme vimos, poderiam ser reduzidas a entidades atuais, na medida em que as coleções fossem submetidas a operações baseadas em certas teorias de conjunto e algébricas (EHRLICH, 2010, p. 245, 255 e 260). No mesmo diapasão, Badiou (2010, p. 71-72) afirma que os resíduos metafísicos do virtual, presentes na teoria das multiplicidades de Deleuze, poderiam ser traduzidos em esquemas baseados na teoria dos conjuntos. Porém, em dissenso, DeLanda (2006, p. 235-236) procura mostrar que, embora seja verdade que a matemática de modo crescente tem incluído problemáticas que pareciam resistentes à axiomatização, novas problemáticas surgem, escapando a uma unificação teórica final, pois, na contracorrente, a heterogeneidade dos modelos tem crescido.

\section{Referências}

AMIEVA, A. L. N. "Introduccion". In: DELEUZE, G. Pintura. El concepto de diagrama (curso que Deleuze ministrou entre 31 de março e 2 de junho de 1981). Buenos Aires: Cactus, 2007. 
ANTONIOLI, M. Géophilosophie de Deleuze et Guattari. Paris: L'Harmattan, 2003.

BADIOU, A. Deleuze: la clameuer de l'Être. s/l: Pluriel, 2010.

CARDOSO JR., H. R. A origem do conceito de multiplicidade segundo Gilles Deleuze. Trans/Form/Ação - Revista de Filosofia, v. 19, p. 151-161, 1996.

. Conceitos onto-políticos no pensamento de Gilles Deleuze: minoria como devir minoritário. Política \& Trabalho, UFPB/João Pessoa, v. 15, 1999, p. 21-28.

. Deleuze, empirismo e pragmatismo - linhas de força do encontro com a teoria dos signos. Síntese, Belo Horizonte, v. 33, 2006, p. 199-211.

Peirce's mathematical-logical approach to discrete collections and the premonition of continuity. Journal of Applied Non-Classical Logic, v. 22, n. 1 (Uses of non-classical logic: foundational issues), 2012, p. 19-41.

DELANDA, M. Deleuze in phase space. In: DUFFY, S. (ed.). Virtual Mathematics: the logic of difference. Bolton: Clinamen Press, 2006. p. 235-247.

DELANDA, M. Intensive science and virtual philosophy. London: Continuum Press, 2002.

DELEUZE, G. Empirisme et subjectivité. Paris: PUF, 1953.

. Logique du sens. Paris: Minuit, 1969.

. Cinéma 1: L'image-mouvement. Paris: Minuit, 1983.

. Cinéma 2: L'image-temps. Paris: Minuit, 1985.

. Foucault. Paris: Minuit, 1986.

. Pourparlers. Paris: Minuit, 1990.

. Prefácio para a edição italiana. In: DELEUZE; GUATTARI. Mil platôs. São Paulo: 34 Letras. v. 3. p. 7-9.

L'actuel et le virtuel (Annexe: Chapitre V). In: DELEUZE, G.; PARNET, C. Dialogues. Flammarion, 1996. p. 179-185.

DELEUZE, G.; BENE, C. Superpositions. Paris: Minuit, 1979.

DELEUZE, G.; GUATTARI, F. Capitalisme et schizophrénie: mille plateaux. Paris: Minuit, 1980.

DELEUZE, G.; PARNET, C. Dialogues. Paris: Flammarion, 1977.

DUFFY, S. Deleuze and mathematics. In: DUFFY, S. (ed.). Virtual Mathematics: the logic of difference. Bolton: Clinamen Press, 2006. p. 1-11.

EHRLICH, Ph. The absolute arithmetic continuum and its peircean counterpart. In: MOORE, M. E. (ed.). New essays on Peirce's mathematical philosophy. Chicago/La Salle, IL, Open Court, 2010. p. 235-281.

ÉRIBON, D. Michel Foucault. São Paulo: Cia. das Letras, 1990.

FERREYRA, J. L'ontologie du Capitalisme chez Gilles Deleuze. Paris: L'Harmattan, 2010.

FOUCAULT, M. História da sexualidade III: o cuidado de si. Rio de Janeiro: Graal, 1985. Vozes, 1999.

Vigiar e Punir: a história da violência nas prisões. 19. ed. Petrópolis/RJ: 
FOUCAULT, M. História da sexualidade 1: a vontade de saber. 14. ed. Rio de Janeiro: Graal, 2001.

GUALANDI, A. Deleuze. Paris: Les Belles Lettres, 1998.

GUATTARI, F.; ROLNIK, S. Micropolítica: cartografias do desejo. 3. ed. Petrópolis: Vozes, 1993.

HARDT, M. Gilles Deleuze: An apprenticeship in philosophy. Minneapolis/London: University of Minnesota Press, 1993.

HAVENEL, J. Peirce's topological concepts. In: MOORE, M. E. (Ed.). New essays on Peirce's mathematical philosophy. Chicago/La Salle, IL, Open Court, 2010. p. 283-322.

MENGUE, Ph. Gilles Deleuze ou le système du multiple. Paris: Kimé, 1994.

. Deleuze et la question de la démocratie. Paris: L'Harmattan, 2003.

MOORE, M. E. Introduction. In: MOORE, M. E. (Ed.). New essays on Peirce's mathematical philosophy. Chicago/La Salle, IL, Open Court, 2010. p. 1-18.

PEIRCE, C. S. Collected papers of Charles Sanders Peirce: Exact logic (published papers) \& the simplest mathematics (v. III-IV). Charles Hartshorne and Paul Weiss (Eds.). Harvard University Press, Belknap Press 1933.

. The new elements of mathematics. C. Eisele (Ed.). The Hague, Netherlands, Mouton Publishers (4 volumes em 5 livros. Também por Atlantic Highlands, NJ: Humanities Press), 1976.

PURDOM, J. Postmodernity as a Spectre of the Future: the force of the capital and the unmasking of the Difference. In: PEARSON, K. A. (Ed.). Deleuze and philosophy: the difference engineer. London and New York: Routledge, 1997. p. 115-129.

THOBURN, N. Deleuze, Marx and Politics. London and New York: Routledge, 2003.

ZIZEK, S. Organes sans corps: Deleuze et consequences. Paris: Éditions Amsterdam, 2008. 